EESTI NSV TEADUSTE AKADEEMIA TOIMETISED 1955. IV kd., nr. 1 ИЗВЕСТИЯ АКАДЕМИИ НАУК ЭСТОНСКОИ ССР 1955. Том IV, 근 1

\title{
ОПРЕДЕЛЕНИЕ ТЕПЛОЗАЩИТНЫХ СВОЙСТВ ОБЛЕГЧЕННЫХ ТИПОВ СТЕН С ВОЗДУШНЫМИ ПРОСЛОЙКАМИ
}

\author{
А. Э. Алумяэ \\ Р. П. РЕИЗМАН, \\ кандидат технических наук
}

Стремление создать каменные, малотеплопроводные стены с минимальным расходом обычно дорогостоящих стеновых материалов привело к появлению ряда облегченных конструкций стен.

Наиболее широкое применение нашли стены с теплоизоляционными засыпками. Однако в условиях Эстонской ССР до настоящего времени отсутствуют эффективные неорганические засыпные утеплители (шлак, минеральная вата и др.), а применение сланцевой золы не всегда дает удовлетворительные результаты. Поэтому в нашей республике применяются стены с воздушными прослойками, которые, по теоретическим расчетам, оказываются достаточно экономичными и малотеплопроводными.

В настоящей статье излагаются результаты натурных определений теплозащитных свойств облегченных стен с воздушными прослойками и дается описание аппаратуры и методики піроведения опытов, обеспечившей получение достаточно надежных результатов при минимальных затратах рабочего времени.

Нами нспытывались два типа стен, показанные на рис. 1 и 2 . Испытания проводились дважды - до и после осуществления наружной штукатурки (зимой 1952/53 и 1953/54 гг.). Опытные участки стен были выведены в 1949/50 г. на четвертом этаже Дома ученых в г. Таллине (бульвар Ленина, д. 5).

Как видно из рис. 1, стена типа 1 выполнена из силикатного кирпича толщиной 38 см и утеплена с внутренней стороны плитами цементного фибролита толщиной 5 см на относе. Стена типа 2 (рис. 2) имеет дополнительные воздушные прослойки толщиной 2 см, что должно улучшить ее теплоизоляционные свойства.

Вычисление теплозащитных свойств стен производилось на основе данных, указанных в таблице $1^{(3)}$.

Вычисленные, а также полученные опытным путем данные о теплозащитных свойствах стен приводятся в таблице 2.

Определенив теплозащитных свойств стен производилось в соответствии с предложенным К. Ф. Фокиным методом обработки экспериментальных данных, являющимся в настоящее время наиболее приемлемым ( $\left.{ }^{1}\right)$. 


\begin{tabular}{|c|c|c|c|c|}
\hline \multirow{2}{*}{ Материал } & \multirow{2}{*}{$\begin{array}{l}\text { Объемный } \\
\text { вес в кг/м }{ }^{3}\end{array}$} & \multirow{2}{*}{$\begin{array}{c}\text { Объемная } \\
\text { влажность } \\
\text { в \% }\end{array}$} & \multicolumn{2}{|c|}{$\begin{array}{c}\text { Коэффициент теплопровод- } \\
\text { ности } \lambda \text { ккал } / \mathrm{M}^{2} \text { час }{ }^{0} \mathrm{C}\end{array}$} \\
\hline & & & $\begin{array}{l}\text { для отрицатель- } \\
\text { ных температур }\end{array}$ & $\begin{array}{l}\text { для положитель- } \\
\text { ных температур }\end{array}$ \\
\hline Штукатурка & 1500 & $5-10$ & 0,520 & 0,465 \\
\hline Цементный фибролит & 400 & 5 & - & $0,144(0,20)^{*}$ \\
\hline Сил̨икатный кирпич & 1800 & $2-5$ & $0.785(0,9)^{*}$ & $0,676(0,9)^{*}$ \\
\hline
\end{tabular}

Таблица 2

\begin{tabular}{|c|c|c|c|c|c|}
\hline \multirow{4}{*}{$\begin{array}{c}\text { Тип } \\
\text { стены }\end{array}$} & \multicolumn{5}{|c|}{ 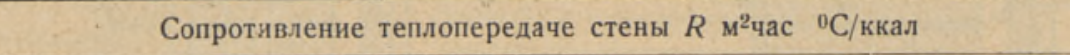 } \\
\hline & \multirow{3}{*}{$\begin{array}{l}\text { Вычисленное } \\
\text { теоретически } \\
\text { (с наружной } \\
\text { штукатуркой) }\end{array}$} & \multicolumn{4}{|c|}{ Полученное опытным путем } \\
\hline & & \multicolumn{2}{|c|}{ без наружной штукатурки } & \multicolumn{2}{|c|}{ с наружной штукатуркой } \\
\hline & & $R$ & $\begin{array}{c}\text { Расхождение по } \\
\text { отношению к } \\
\text { теоретическому } \\
\text { значению в \% }\end{array}$ & $R$ & $\begin{array}{c}\text { Расхождение по } \\
\text { отношению к } \\
\text { теоретическому } \\
\text { значению в \% }\end{array}$ \\
\hline Тип 1 & $1,31(1,12)^{* * *}$ & 0,89 & -32 & 0,96 & -27 \\
\hline Тип 2 & $1,58(1,46, * *$ & 0,98 & -38 & 1,35 & -14 \\
\hline
\end{tabular}

При этом методе необходимо определять величину теплового потока, протекающего через стену, и температуры отдельных слоев стены. Как показывает практика Института строительства и строительных материалов АН ЭССР, единовременные срочные замеры этих величин могут оказаться ненадежными, так как возможны весьма большие кратковременные их колебания, зависящие от различных случайных причин. Особенно большим колебаниям подверждены величины теплового потока и температуры слоев стены, прилегающих к наружной и внутренней поверхностям ограждения.

Сектором строительства и архитектуры Института уже в продолжении трех лет с успехом применяется установка, автоматически записывающая в течение круглых суток необходимые данные. Это позволяет получать надежные данные, значительно сократить расход рабочего времени на проведение замеров и производить эксперименты в эксплуатирующихся помещениях.

Измерение тепловых потоков пронзводилось тепломером, состоящим из 600-800 дифференциальных термопар. Такие тепломеры изготавливаются и тарируются Ленинградским институтом холодильной и молочной промышленности. Большое количество соединенных последовательно термопар позволяет получить при малых значениях тепловых потоков значительные термотоки. Эти термотоки можно записывать с достаточной точностью непосредственно, без промежуточного усиления, самопишущим прибором обычного типа.

Измерение температур по слоям стен производилось медными термометрами сопротивления, изготовленными и тарированными в Институте

* В скобках дается значение $\lambda$ при увлажненных материалах.

** В скобках дается значение $R$ при увлажненных материалах. 
так, что при $0^{\circ} \mathrm{C}$ они имеют сопротивление $100 \Omega$. Места установки термометров показаны на рис. 1 и 2.

Для осуществления автоматической записи термотоков и температур, измеряемых термометрами сопротивления, обыкновенно применяются два прибора - гальванометр или потенциометр и автоматический мост. Институт, пользуясь только самопишущим гальванометром, осуществил схему, позволяющую на одном приборе записывать и термотоки, и величины сопротивлений термометров.

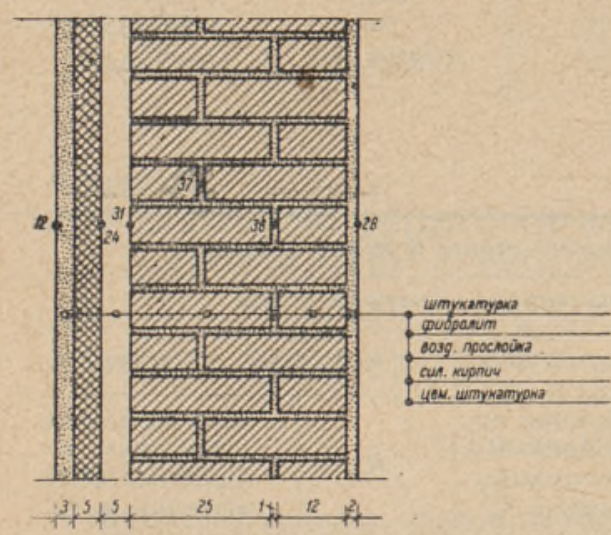

Рис. 1. Конструкция облегченной стены с одной воздушной прослойкой (тип 1).

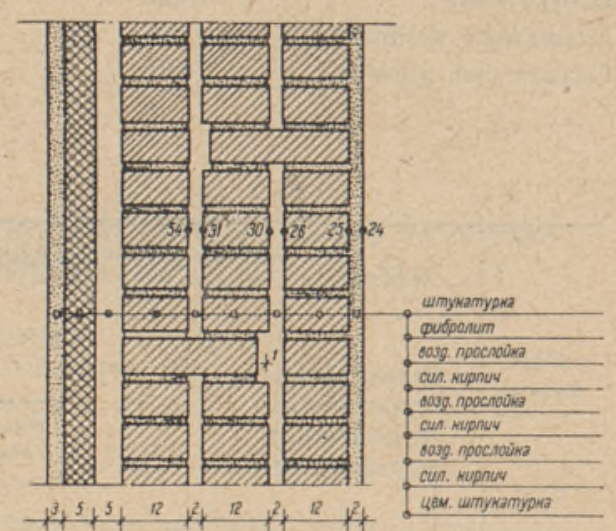

Рис. 2. Конструкция облегченной стены с тремя воздушными прослойками (тип 2).

(Черные-точки указывают места установки термометроз сопротивлегия; цифры - их лабораторные номера.)

В схеме (рис. 3) был применен гальванометр с записью шести точек. Пять точек использовались для записи температур, измеряемых термометрами сопротивления, шестая точка - для записи термотоков тепломера.

Измерение сопротивлений термометров производилось по схеме неуравновешенного моста, питаемого от аккумулятора напряжением $2 \mathrm{~V}$, емкостью 60 ампер-часов. В качестве измерителя был применен гальванометр самопишущего прибора. Для этого в разрыв провода, соединяющего переключатель самописца с гальванометром (точки $a$ и б), была присоединена схема неуравновешенного моста. Добавочное сопротивление самописца (не показанное на схеме) было отключено, чтобы повысить чувствительность гальванометра. К пяти точкам переключателя самописца подключались термометры сопротивления, к шестой - телефонное реле с сопротивлением обмотки около $100 \Omega$. Плечи неуравновешенного моста были подобраны так, чтобы запись сопротивлений термометров на шкале самописца могла обеспечить измерение температур в пределах от $-20^{\circ} \mathrm{C}$ до $+20^{\circ} \mathrm{C}$. При установке переключателя на шестой точке срабатывало телефонное реле, включавшее вторичное реле (на схеме не показано), которое, изменяя положение ртутного контакта, включало тепломер в цепь гальванометра, одновременно отключая схему неуравновешенного моста от самописца. Таким образом, на ленте самописца получалась запись сопротивлений пяти термометров и термотоков от одного тепломера.

Для возможности дешифровки ленты самописца вся схема калибровалась дважды - в начале и в конце эксперимента, для чего вместо термометров включались сопротивлениึя, соответствовавшие сопротивлениям термометров при температурах $-20^{\circ} \mathrm{C}$ и выше, через $5^{\circ} \mathrm{C}$, а вместо термо- 


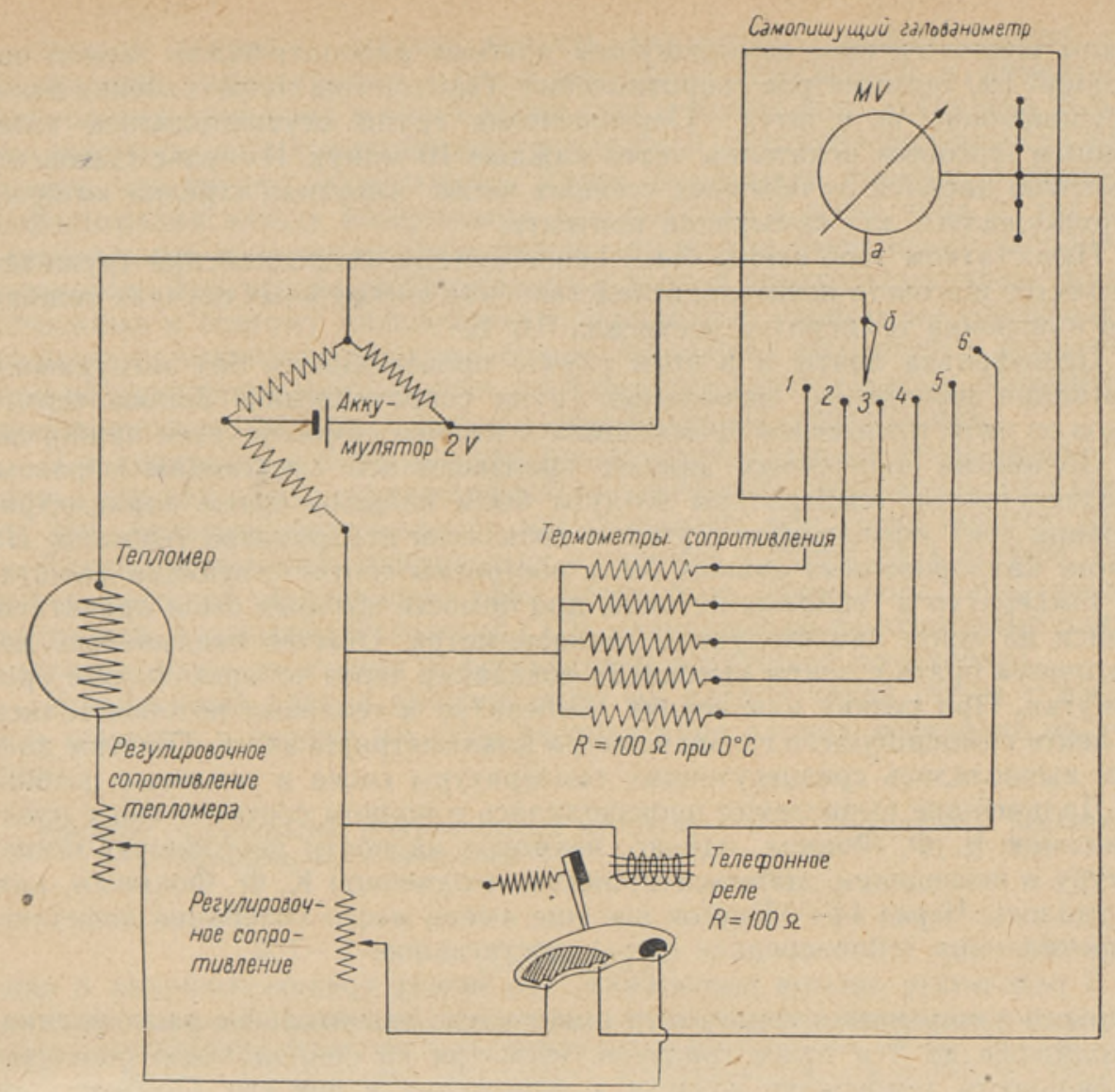

Рис. 3. Принципнальная схема автоматической установки для записи сопротивлений термометров сопротивления и термотоков тепломера.

токов тепломера подавалось соответствующее напряжение от делителя напряжения. Контроль подаваемого напряжения осуществлялся лабораторным потенциометром.

При проведении эксперимента один раз в сутки производились осмотр схемы и замеры сопротивлений термометров лабораторным мостом Уитстона, на что затрачивалось около 0,5 часа.

Температура воздуха в помещении и наружного воздуха записывалась недельными термографами обычного метеорологического типа, а влажность воздуха в помещении - недельным гигрографом. Показания самописцев ежедневно проверялись психрометром Ассмана.

Опыт продолжался обычно около двух недель, после чего производилась дешифровка ленты самописца и вычисление сопротивления теплопередаче стены.

Измерение температур с помощью описываемой схемы возможно с точностью $\pm 0,3^{\circ} \mathrm{C}$, что является вполне достаточным для получения надежных результатов. Сопротивления термометров, записанные схемой и измеренные лабораторным мостом Уитстона, практически совпадали.

В целом схема работала вполне устойчиво и может быть рекомендована для практического применения.

Ранее, при проведении испытаний ограждающих конструкций в опытном павильоне, Институтом была осуществлена по аналогичной схеме при 
одном шеститочечном самопишущем приборе автоматическая запись показаний 180 термометров сопротивлений. Термометры сопротивления были сгруппированы по 6 штук. Переключение групп осуществлялось телефонным шаговым искателем через каждые 10 минут. Импульс шаговому искателю давался от обычных стенных часов, минутная стрелка которых использовалась для замыкания контакта.

Недостатком этой схемы было непостоянство сопротивлений трущихся контактов шагового искателя, вследствие чего в отдельных случаях ошибка при измерении температур достигала $0,6^{\circ} \mathrm{C}$.

Дешифровка ленты и в этом случае производилась без затруднений благодаря включению сигнальных групп сопротивлений. Запись термотоков от пяти тепломеров производилась вторым самопишущим прибором.

Обработка полученных данных производилась следующим образом. Среднесуточные температуры воздуха были найдены путем планиметрирования лент термографов с учетом показаний психрометра Ассмана. На основе калибровочных данных были построены соответствующие масштабы температур и тепловых потоков, при помощи которых были прочитаны записи на ленте самопишущего гальванометра. Обычно оказывалось достаточным брать с ленты самописца показания через четырехчасовые промежутки. При резких изменениях температур и тепловых потоков записи на ленте самопишущего гальванометра планиметрировались. По этим данным вычислялись среднесуточные температуры слоев и тепловые потоки.

Дальнейшие вычисления производились в полном соответствии с предложением К. Ф. Фокина, однако, несмотря на почти постоянную температуру в помещении, добиться точности, полученной К. Ф. Фокиным, нам не удалось. Через 14-15 суток все еще имели место колебания величины сопротивления теплопередаче стены, достигавшие $3-7 \%$.

В результате опытов выяснилось, что между среднесуточными и единичными измерениями температур имеет место значительное расхождение, доходившее до 3 и более градусов, несмотря на сравнительно большую стабильность температур воздуха в помещении и вне его. Особенно же большие отклонения от среднесуточных величин, доходившие до $50 \%$, претерпевал тепловой поток.

При принятом методе вычисления ошибки в измерении температур слоев стены не вызывают чрезмерно больших ошибок в определении $R$ стены. В наших опытах ошибка не превышала $10 \%$. При попытке же пронзвести вычисления $R$ стены, пользуясь единичными измерениями теплового потока и температур воздуха внутри и вне помещения, были получены недопустимо большие расхождения. Таким образом, можно сделать бесспорный вывод, что такая непрерывная запись температур и тепловых потоков позволяет резко улучшить точность результатов при определении сопротивления теплопередаче ограждающих конструкций.

В результате проведенных экспериментальных исследований удалось выяснить, что теплозащитные свойства рассматриваемых стен облегченных типов в действительности оказались значительно меньшими, чем это можно было ожидать на основании теоретических расчетов (табл. 2). Одной из причин этого может быть занижение коэффициентов теплопроводностй отдельных строительных материалов против действительных. Вследствие повышенной влажности силикатного кирпича и фибролита в течение первых двух лет эксплуатации здания можно ожидать более высоких значений коэффициента теплопроводности строительных материалов (табл. 1, цифры в скобках), соответственно которым получаются и значения теплозащитных свойств стены (табл. 2, в екобках), более близкие к полученным опытным путем. К сожалению, взять пробы материала на влажность нам не удалось. 
Второй причиной следует считать внутреннюю инфильтрацию $\left({ }^{2}\right)$. Внутренняя инфильтрация между воздушной прослойкой и цементным фибролитом возможна в обоих типах стен и может быть устранена только оштукатуриванием прилегающей к воздушной прослойке поверхности фибролита, что трудно осуществимо. Далее, безусловно имеется внутренняя инфильтрация между воздушными прослойками в стене типа 2, так как вертикальные поперечные швы между кирпичами были плохо заполнены раствором. Внутренняя инфильтрация в данной конструкции стены трудно устранима и поэтому понижение теплозащитных свойств по сравнению с теоретическими значениями неизбежно. Наружная штукатурка, резко снижая воздухопроницаемость стен, способствует значительному повышению теплозащитных свойств подобных ограждающих конструкций.

Для внедрения в стронтельство предпочтительным является второй тип стены, так как при одинаковом расходе материала стена этого типа имеет на $35 \%$ большее сопротивление теплопередаче, чем стена первого типа.

Такая стена может применяться в зданиях высотой до 4 этажей, причем в качестве утепляющего слоя могут быть применены гипсолитовые плиты или, в условиях Әстонской ССР, сланцезольно-пенобетонные плиты, расположенные на относе (с оставлением воздушной прослойки).

Повышенный расход рабочей силы на кладку такой стены с избытком окупится в первые же годы эксплуатации здания экономией на топ: ливе.

Институт строительства и строительных материалов Академии наук Әстонской ССР

Поступила в редакцию $15 \times 1954$

\section{ЛИТЕРАТУРА}

1. К. Ф. Фокин, Применение тепломера для определения теплозащитных свойств наружных ограждений, Исследования по строительной физике, Москва, 1949.

2. К. Ф. Ф о к и н, Строительная теплотехника ограждающих частей зданий, Москва, 1953.

3. А. У. Ф р а ч у к, Таблицы теплотехнических показателей строительных материалов, Москва, 1949. 